\title{
Os desafios das Administrações Municipais na terceirização de serviços
}

The challenges of Municipal Administrations in outsourcing services

\author{
Maira Coutinho Ferreira Giroto ${ }^{1}$
}

\section{RESUMO}

O presente artigo trata do risco de as diferentes modalidades de terceirização no âmbito da Administração municipal se enquadrarem no conceito de despesa com pessoal da Lei de Responsabilidade Fiscal, do risco de interrupção dos serviços de saúde públicos em razão da dificuldade de contratação de profissionais e do risco de a Administração vir a responder por encargos trabalhistas e previdenciários não adimplidos pelas empresas contratadas. Propõe como prevenção de tais riscos o melhor planejamento das terceirizações, com foco nos resultados e buscando a eficiência, eficácia e efetividade dos serviços públicos e nos mecanismos de controle dos contratos e parcerias firmados.

Palavras-chave: Terceirização. Lei de Responsabilidade Fiscal. Administração municipal. Serviços públicos.

\section{ABSTRACT}

This paper tackles the risk of different types of outsourcing within the Municipal Administration may be included in the concept of personnel expenses defined by the Fiscal Responsibility Law, the risk of public health services interruption due to the difficulty in hiring staff and the risk that the

\footnotetext{
$1 \quad$ Agente da Fiscalização do Tribunal de Contas do Estado de São Paulo. Doutora em Linguística e Língua Portuguesa pela UNESP, especialista em Direito Público pela PUC Minas e especialista em Direito Administrativo pela UNIARA. E-mail: maira@adv.oabsp.org.br.
} 
Administration may have to take responsibility for labor and social security charges which were not paid by contracted companies. In order to avoid those risks, this paper suggests a better outsourcing planning, focusing on results and on achieving efficiency and effectiveness in public services and on controlling mechanisms of the contracts and partnerships signed.

Keywords: Outsourcing. Fiscal Responsibility Law. Municipal Administration. Public services.

\section{INTRODUÇÃO}

Muitas são as dificuldades enfrentadas pela Administração Pública quando a execução indireta, ou seja, pela iniciativa privada, de serviços de interesse público se apresenta como opção mais vantajosa do que a execução direta por servidores, empregados públicos e recursos materiais próprios.

O presente artigo tem como foco três dos muitos problemas enfrentados nesse contexto: o risco de as despesas referentes à terceirização se enquadrarem no conceito de despesa com pessoal definido pela Lei Complementar $n^{\circ} 101 / 2000$, prejudicando o desempenho fiscal do município; o risco de interrupção dos serviços de saúde públicos em razão da dificuldade de contratação de profissionais para essa área tão essencial para a população; e o risco de a Administração vir a responder por encargos trabalhistas e previdenciários não adimplidos pelas empresas ou entidades privadas responsáveis pela execução indireta de serviços públicos.

O principal caminho apresentado neste artigo para a redução desses riscos consiste no melhor planejamento das terceirizações, de modo que as parcerias com a iniciativa privada sejam formalizadas com foco nos resultados, buscando a eficiência, a eficácia e a efetividade dos serviços, e não na simples substituição de pessoal próprio da Administração por pessoal terceirizado, e com mecanismos de controle do adimplemento das obrigações acessórias afetas aos contratos que envolvem mão de obra (em especial, os encargos trabalhistas e previdenciários). 


\subsection{O LIMITE DA LEI DE RESPONSABILIDADE FISCAL PARA A DESPESA COM PESSOAL DO PODER EXECUTIVO NA ESFERA MUNICIPAL}

A Lei Complementar $n^{\circ}$ 101/2000, Lei de Responsabilidade Fiscal, estabelece que a despesa total com pessoal do Poder Executivo na esfera municipal, em cada período de apuração, não poderá exceder cinquenta e quatro por cento da receita corrente líquida (arts. 19 e 20, inciso III, alínea b).

O cômputo das despesas dessa natureza, para fins de cálculo do referido limite, deve considerar, além da Prefeitura, todas as entidades da Administração indireta, tendo em vista que a receita corrente líquida do município compreende as receitas de todas essas entidades (BRUNO, 2011).

A intenção do legislador foi a de frear o permanente e contínuo aumento das despesas com pessoal, em um contexto em que:

\footnotetext{
Inúmeros entes da Federação, principalmente Municípios, tinham valores despendidos com folha de pagamento bastante elevados para a capacidade arrecadatória, trazendo enormes prejuízos à comunidade que representavam, com percentuais inimagináveis em relação aos valores gastos com pessoal e consequente prejuízo das despesas básicas da administração, como saúde, educação, transporte, enfim, prestação de serviços públicos em geral, finalidade precípua da instituição Estado, em sentido lato. (BRUNO, 2011, p. 173)
}

$\mathrm{O}$ art. 18 da lei define despesa total com pessoal como o somatório dos gastos do ente da Federação com os ativos, os inativos e os pensionistas, relativos a mandatos eletivos, cargos, funções ou empregos, civis, militares e de membros de Poder, com quaisquer espécies remuneratórias, tais como vencimentos e vantagens, fixas e variáveis, subsídios, proventos da aposentadoria, reformas e pensões, inclusive adicionais, gratificações, horas extras e vantagens pessoais de qualquer natureza, bem como encargos sociais e contribuições recolhidas pelo ente às entidades de previdência. 
$\mathrm{O} \S 1^{\circ}$ do mesmo artigo inclui na despesa com pessoal, também, os valores dos contratos de terceirização de mão de obra que se referem à substituição de servidores e empregados públicos, que devem ser contabilizados como "Outras Despesas de Pessoal".

A proximidade do montante da despesa com pessoal, como o limite imposto pela Lei de Responsabilidade Fiscal, não raro impede que o gestor municipal realize concurso público ou processo seletivo (previstos nos incisos II e IX do art. 37 da Constituição Federal) para contratação de profissionais necessários às atividades administrativas e para prestação de serviços públicos à população. A situação é ainda mais crítica quando há queda na arrecadação de receitas, ocasionando aumento do percentual representado pela despesa com pessoal em relação ao montante da receita corrente líquida.

Nesses casos, frequentemente opta-se por terceirizar as atividades e os serviços essenciais ou que não possam ser interrompidos, o que não necessariamente evita o aumento da despesa com pessoal exatamente por esses contratos terem por objeto a substituição do trabalho daqueles servidores e empregados públicos que se evitou contratar, enquadrando-se na espécie de despesa com pessoal definida pelo citado parágrafo primeiro do art. 18 da Lei de Responsabilidade Fiscal.

Além disso, a intenção do legislador com a obrigatoriedade da contabilização das despesas vinculadas a esses contratos como "Outras Despesas de Pessoal" foi exatamente a de coibir a utilização da terceirização de mão de obra como artifício para a contratação e o pagamento de pessoal superior ao percentual máximo imposto por esse dispositivo legal, o que vai de encontro ao equilíbrio entre receitas e despesas e à imposição de limite aos gastos dessa natureza almejados pela Lei Fiscal (BRUNO, 2011).

Nesse ponto, reside a importância de se realizar terceirizações de serviços dentro das possibilidades previstas pela legislação nacional que, ao mesmo tempo, não se enquadrem na hipótese prevista pelo parágrafo primeiro do art. 18, em sua forma e em sua essência, e alcancem os re- 
sultados pretendidos pelo gestor municipal e necessários para a estrutura administrativa e para a população.

\section{A TERCEIRIZAÇÃO NA ADMINISTRAÇÃO PÚBLICA}

Entre as medidas adotadas com o objetivo de diminuir o tamanho do Estado, estão compreendidos os acordos de variados tipos pelos quais a Administração Pública busca a colaboração do setor privado, sendo exemplos típicos os convênios e os contratos de obras e prestação de serviços, entre os quais se enquadra o instituto da terceirização (DI PIETRO, 2012).

Ensina Di Pietro (2012) que, no âmbito da Administração Pública, a terceirização como contrato de fornecimento de mão de obra não tem guarida em razão da exigência constitucional de concurso público para a investidura em cargos, empregos ou funções, tendo por exceção apenas a contratação temporária prevista no inciso IX da Carta Magna, sendo possível somente a terceirização como contrato de prestação de serviços.

Os contratos de prestação de serviços com mão de obra residente envolvem a dedicação direta e exclusiva dos profissionais do contratado à contratante, seja em suas dependências ou nas de terceiros, e, em geral, envolvem serviços de limpeza, conservação, vigilância, brigada, copeiragem, apoio administrativo etc. (BRASIL, 2013).

Estes representam, em tese, maior risco quanto à possibilidade de responsabilização subsidiária da Administração por encargos trabalhistas, pela via judicial, pois o convívio e a proximidade dos empregados do contratado com os funcionários públicos e as instalações físicas da Administração facilitam a caracterização da habitualidade e da subordinação, típicas do vínculo empregatício delineado nos arts. $2^{\circ}$ e $3^{\circ}$ do Decreto-Lei $\mathrm{n}^{\circ} 5.452 / 1943$. Por conseguinte, representam, também, maior risco de enquadramento nas “Outras Despesas de Pessoal” descritas no $\S 1^{\circ}$ do art. 18 da Lei de Responsabilidade Fiscal. 
Os contratos sem mão de obra residente, por outro lado, são aqueles cujo objeto corresponde à execução de uma atividade destinada a obter determinado resultado de interesse, um produto específico definido pela Administração contratante, por exemplo, conserto, instalação, montagem, operação, conservação, reparação, adaptação, manutenção, transporte, locação de bens, publicidade, seguro ou trabalhos técnico-profissionais (BRASIL, 2013). A seção 6 deste artigo é dedicada aos contratos dessa natureza.

\section{RESPONSABILIDADE DO MUNICÍPIO POR OBRIGAÇÕES PREVIDENCIÁRIAS E TRABALHISTAS}

$\mathrm{O} \S 2^{\circ}$ do art. 121 da Lei Federal $n^{\circ}$ 14.133/2021 estabelece que, exclusivamente nas contratações de serviços contínuos com regime de dedicação exclusiva de mão de obra, a Administração responderá solidariamente pelos encargos previdenciários e subsidiariamente pelos encargos trabalhistas, quando comprovada falha na fiscalização do cumprimento das obrigações do contratado. $\mathrm{O} \S 5^{\circ}$ do mesmo dispositivo determina que o recolhimento das contribuições previdenciárias observe o disposto no art. 31 da Lei $n^{\circ} 8.212 / 1991$.

O mencionado art. 31 trata da retenção, pela empresa contratante de serviços executados mediante cessão de mão de obra, inclusive em regime de trabalho temporário, sobre o valor bruto da nota fiscal ou fatura de prestação de serviços e recolhimento em nome da empresa cedente da mão de obra. Ou seja, a responsabilidade solidária do município pelos encargos previdenciários se restringe à parte patronal somente nos contratos de prestação de serviços contínuos com regime de dedicação exclusiva de mão de obra e depende da comprovação de falha na fiscalização do cumprimento das obrigações do contratado.

Lembramos que, no âmbito da Administração Pública, esses contratos somente podem ter por objeto a prestação de serviços relacionada a atividades-meio, pois a terceirização de atividades relacionadas à área-fim 
de um órgão ou entidade pública ou que estejam incluídas nas atribuições de seus cargos ou empregos públicos ofende a regra constitucional do concurso público. Esse entendimento está claro no voto do ministro relator do processo TC-032.202/2010-5, do Tribunal de Contas da União (Acórdão $n^{0} 5216 / 2012$ - $1^{\text {a }}$ Câmara), e na Instrução Normativa no 5/2017, do Ministério do Planejamento, Desenvolvimento e Gestão, que assim dispõe:

\begin{abstract}
Art. $9^{\circ}$ Não serão objeto de execução indireta na Administração Pública federal direta, autárquica e fundacional:

I - atividades que envolvam a tomada de decisão ou posicionamento institucional nas áreas de planejamento, coordenação, supervisão e controle;

II - as atividades consideradas estratégicas para o órgão ou entidade, cuja terceirização possa colocar em risco o controle de processos e de conhecimentos e tecnologias;

III - as funções relacionadas ao poder de polícia, de regulação, de outorga de serviços públicos e de aplicação de sanção; e IV - as atividades inerentes às categorias funcionais abrangidas pelo plano de cargos do órgão ou entidade, salvo expressa disposição legal em contrário ou quando se tratar de cargo extinto, total ou parcialmente, no âmbito do quadro geral de pessoal.

Parágrafo único. As atividades auxiliares, instrumentais ou acessórias às funções e atividades definidas nos incisos do caput podem ser executadas de forma indireta, sendo vedada a transferência de responsabilidade para realização de atos administrativos ou a tomada de decisão para o contratado.
\end{abstract}

Quanto à responsabilidade por encargos trabalhistas, o $\S 1^{\circ}$ do art. 71 da Lei $n^{\circ} 8.666 / 93$ dispõe que a inadimplência do contratado com referência a essas obrigações não transfere à Administração Pública a responsabilidade por seu pagamento. O já citado teor do $\S 2^{\circ}$ do art. 121 da Lei Federal $n^{\circ} 14.133 / 2021$, que substituirá a Lei $n^{\circ} 8.666 / 93^{2}$, compatibilizou a norma geral de licitações e contratos, no tocante à responsabilidade subsidiária do município, à Súmula no 331 do Tribunal Superior do Trabalho, que assim dispõe (grifos nossos):

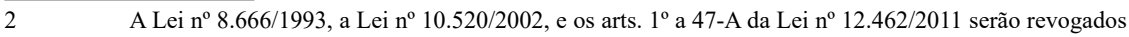
após decorridos dois anos da publicação oficial da Lei ${ }^{\circ}$ 14.133/2021. 
CONTRATO DE PRESTAÇÃO DE SERVIÇOS. LEGALIDA$\mathrm{DE}$ (nova redação do item IV e inseridos os itens V e VI à redação) - Res. 174/2011, DEJT divulgado em 27, 30 e 31.05.2011

$[\ldots]$

IV - O inadimplemento das obrigações trabalhistas, por parte do empregador, implica a responsabilidade subsidiária do tomador dos serviços quanto àquelas obrigações, desde que haja participado da relação processual e conste também do título executivo judicial.

V - Os entes integrantes da Administração Pública direta e indireta respondem subsidiariamente, nas mesmas condições do item IV, caso evidenciada a sua conduta culposa no cumprimento das obrigações da Lei $n^{0}$ 8.666, de 21.06.1993, especialmente na fiscalização do cumprimento das obrigações contratuais e legais da prestadora de serviço como empregadora. A aludida responsabilidade não decorre de mero inadimplemento das obrigações trabalhistas assumidas pela empresa regularmente contratada.

Da redação do citado inciso $\mathrm{V}$, infere-se a importância da regulamentação dos procedimentos de gestão e de fiscalização das execuções contratuais, por parte dos municípios, que inclua procedimentos específicos de fiscalização do cumprimento das obrigações trabalhistas por parte das empresas contratadas para a prestação de serviços.

\section{FISCALIZAÇÃO DO CUMPRIMENTO DE OBRIGAÇÕES TRABALHISTAS}

A gestão e a fiscalização de contratos compreendem todos os atos e os procedimentos realizados por órgãos e agentes públicos para garantir que os contratos administrativos atendam às finalidades para as quais foram firmados, ou seja, a perfeita execução do objeto e a decorrente obtenção de benefícios para a população e para a Administração contratante, com o melhor aproveitamento possível dos recursos públicos investidos, a prevenção e a reparação de danos e prejuízos ao erário. 
$\mathrm{O}$ art. 117 da Lei $\mathrm{n}^{\circ}$ 14.133/2021 exige que a execução do contrato seja acompanhada e fiscalizada por, no mínimo, um servidor ou empregado público especialmente designado. Entretanto, os atos e os procedimentos que concretizam essa obrigação legal devem ser regulamentados internamente pela Administração, inclusive no que se refere à fiscalização do cumprimento, pelo contratado, das obrigações trabalhistas afetas ao contrato, com o objetivo de evitar a já mencionada responsabilização subsidiária.

O Quadro 1 apresenta exemplos de procedimentos de fiscalização do cumprimento de obrigações trabalhistas pelo contratado que podem ser incluídos, com as necessárias adaptações, tanto na regulamentação interna de gestão e fiscalização de contratos quanto nos editais, em contratos e nos respectivos anexos dos processos de licitação que envolvem prestação de serviços. Foi utilizada como fonte a Instrução Normativa n ${ }^{\circ}$ 5/2017 do Ministério do Planejamento, Desenvolvimento e Gestão, que dispõe sobre as regras e as diretrizes do procedimento de contratação de serviços sob o regime de execução indireta no âmbito da Administração Pública federal direta, autárquica e fundacional. 
Quadro 1 - Exemplos de procedimentos de fiscalização do cumprimento de obrigações trabalhistas

\begin{tabular}{|c|c|}
\hline \multirow{8}{*}{$\begin{array}{l}\text { Fiscalização } \\
\text { inicial }\end{array}$} & $\begin{array}{l}\text { Elaborar planilha-resumo de todo o contrato administrativo com informações sobre } \\
\text { todos os empregados terceirizados que prestam os serviços (nome completo, núme- } \\
\text { ro do CPF, função exercida, salário, adicionais, gratificações, benefícios recebidos } \\
\text { (como vale-transporte e auxílio-alimentação), horário de trabalho, férias, licenças, } \\
\text { faltas, ocorrências e horas extras trabalhadas). }\end{array}$ \\
\hline & $\begin{array}{l}\text { Fiscalizar as Carteiras de Trabalho e Previdência Social (CTPS) por amostragem, } \\
\text { conferindo todas as anotações nelas contidas para que se possa verificar se as infor- } \\
\text { mações coincidem com as informações fornecidas pela empresa e pelo empregado, } \\
\text { com especial atenção à data de início do contrato de trabalho, função exercida, re- } \\
\text { muneração (corretamente discriminada em salário-base, adicionais e gratificações) } \\
\text { e eventuais alterações dos contratos de trabalho. }\end{array}$ \\
\hline & $\begin{array}{l}\text { Verificar se o número de terceirizados por função coincide com o previsto no } \\
\text { contrato administrativo. }\end{array}$ \\
\hline & $\begin{array}{l}\text { Verificar se o salário não é inferior ao previsto no contrato administrativo e na } \\
\text { Convenção Coletiva de Trabalho da Categoria (CCT). }\end{array}$ \\
\hline & $\begin{array}{l}\text { Consultar eventuais obrigações adicionais constantes na CCT para as empresas } \\
\text { terceirizadas (por exemplo, se os empregados têm direito a auxílio-alimentação). }\end{array}$ \\
\hline & $\begin{array}{l}\text { Verificar a existência de condições insalubres ou de periculosidade no local de } \\
\text { trabalho, que ensejam pagamento dos respectivos adicionais aos empregados e/ou } \\
\text { fornecimento, pelo contratado, de Equipamentos de Proteção Individual (EPI). }\end{array}$ \\
\hline & $\begin{array}{c}\text { Verificar as CTPS dos responsáveis técnicos pela execução dos serviços, (quando } \\
\text { houver) devidamente assinadas pelo contratado. }\end{array}$ \\
\hline & $\begin{array}{l}\text { Verificar os exames médicos admissionais dos empregados do contratado que } \\
\text { prestarão os serviços. }\end{array}$ \\
\hline \multirow{3}{*}{$\begin{array}{c}\text { Fiscalização } \\
\text { mensal }\end{array}$} & $\begin{array}{l}\text { Reter a contribuição previdenciária no valor de onze por cento sobre o valor da } \\
\text { fatura e dos impostos incidentes sobre a prestação do serviço (nos casos de cessão } \\
\text { de mão de obra para serviços afetos a atividades-meio). }\end{array}$ \\
\hline & $\begin{array}{c}\text { Exigir a certidão de regularidade relativa a Créditos Tributários Federais e à Dívida } \\
\text { Ativa da União, o Certificado de Regularidade do FGTS (CRF) e a Certidão } \\
\text { Negativa de Débitos Trabalhistas (CNDT), ou outra forma de comprovação de } \\
\text { atendimento ao inciso XIII do art. } 55 \text { da Lei n }{ }^{\circ} 8.666 / 93 \text {. }\end{array}$ \\
\hline & $\begin{array}{l}\text { Exigir, quando couber, comprovação de que a empresa mantém reserva de cargos } \\
\text { para pessoa com deficiência ou para reabilitado da Previdência Social, conforme } \\
\text { disposto no art. 66-A da Lei } n^{\circ} 8.666 / 93 \text {. }\end{array}$ \\
\hline \multirow{3}{*}{$\begin{array}{l}\text { Fiscalização } \\
\text { diária }\end{array}$} & $\begin{array}{l}\text { Evitar ordens diretas da Administração, eventuais reclamações ou cobranças dirigi- } \\
\text { das aos terceirizados, pois devem ser encaminhadas ao preposto da empresa. }\end{array}$ \\
\hline & $\begin{array}{l}\text { Evitar toda e qualquer alteração na forma de prestação do serviço, como a nego- } \\
\text { ciação de folgas ou a compensação de jornada, pois essa conduta é exclusiva do } \\
\text { empregador. }\end{array}$ \\
\hline & $\begin{array}{l}\text { Conferir por amostragem, diariamente, os empregados terceirizados que estão pres- } \\
\text { tando serviços e em quais funções, e se estão cumprindo a jornada de trabalho. }\end{array}$ \\
\hline
\end{tabular}

Rev. Controle, Fortaleza, v.19, n.2, p. 268-299, jul./dez. 2021. 
Quadro 1 - Exemplos de procedimentos de fiscalização do cumprimento de obrigações trabalhistas (continuação)

\begin{tabular}{|c|c|}
\hline \multirow{3}{*}{$\begin{array}{c}\text { Fiscalização } \\
\text { procedimental }\end{array}$} & $\begin{array}{l}\text { Observar a data-base da categoria prevista na CCT, pois os reajustes dos empre- } \\
\text { gados devem ser obrigatoriamente concedidos pela empresa no dia e percentual } \\
\text { previstos. }\end{array}$ \\
\hline & $\begin{array}{l}\text { Certificar-se de que a empresa observa a legislação relativa à concessão de férias e } \\
\text { licenças aos empregados. }\end{array}$ \\
\hline & $\begin{array}{l}\text { Certificar-se de que a empresa respeita a estabilidade provisória de seus emprega- } \\
\text { dos (cipeiro, gestante e estabilidade acidentária). }\end{array}$ \\
\hline \multirow[b]{3}{*}{$\begin{array}{l}\text { Fiscalização } \\
\text { por } \\
\text { amostragem }\end{array}$} & $\begin{array}{l}\text { Solicitar, por amostragem, aos empregados que verifiquem se as contribuições } \\
\text { previdenciárias e do FGTS estão ou não sendo recolhidas em seus nomes. }\end{array}$ \\
\hline & $\begin{array}{l}\text { Solicitar, por amostragem, aos empregados terceirizados os extratos da conta do } \\
\text { FGTS, os quais devem ser entregues à Administração. }\end{array}$ \\
\hline & $\begin{array}{l}\text { O contratado deverá entregar, no prazo de } 15 \text { dias, quando solicitado pela Adminis- } \\
\text { tração, por amostragem, quaisquer dos seguintes documentos: extrato da conta do } \\
\text { INSS e do FGTS de qualquer empregado, a critério da Administração contratante; } \\
\text { cópia da folha de pagamento analítica de qualquer mês da prestação dos servi- } \\
\text { ços, em que conste como tomador o órgão ou a entidade contratante; cópia dos } \\
\text { contracheques assinados dos empregados relativos a qualquer mês da prestação } \\
\text { dos serviços ou, ainda, quando necessário, cópia de recibos de depósitos bancários; } \\
\text { e comprovantes de entrega de benefícios suplementares (vale-transporte, vale-a- } \\
\text { limentação etc.) relativos a qualquer mês da prestação dos serviços e de qualquer } \\
\text { empregado. }\end{array}$ \\
\hline \multirow[b]{2}{*}{$\begin{array}{c}\text { Havendo } \\
\text { indício de } \\
\text { irregularidade }\end{array}$} & $\begin{array}{l}\text { Quanto ao recolhimento das contribuições previdenciárias, oficiar à Receita Federal } \\
\text { do Brasil (RFB). Já quanto ao recolhimento da contribuição para o FGTS, oficiar } \\
\text { ao Ministério do Trabalho. }\end{array}$ \\
\hline & $\begin{array}{l}\text { O descumprimento das obrigações trabalhistas ou a não manutenção das condições } \\
\text { de habilitação pelo contratado poderá dar ensejo à rescisão contratual (sem prejuízo } \\
\text { das demais sanções), sendo possível conceder um prazo para que a contratada regu- } \\
\text { larize o problema, sob pena de rescisão contratual, quando não identificar má-fé ou } \\
\text { a incapacidade da empresa de corrigir. }\end{array}$ \\
\hline $\begin{array}{l}\text { Término da } \\
\text { vigência ou } \\
\text { rescisão do } \\
\text { contrato }\end{array}$ & $\begin{array}{l}\text { Verificar o pagamento pelo contratado das verbas rescisórias ou dos documentos } \\
\text { que comprovem que os empregados serão realocados em outra atividade de presta- } \\
\text { ção de serviços, sem que ocorra a interrupção do contrato de trabalho. }\end{array}$ \\
\hline
\end{tabular}

Fonte: Adaptado da Instrução Normativa n ${ }^{\circ}$ 5/2017 do Ministério do Planejamento, Desenvolvimento e Gestão.

\section{Procedimentos desse tipo exigem planejamento, tempo e dedicação dos gestores e fiscais de contratos; por isso, é importante que os estudos prévios à abertura de processos de licitação de serviços que ensejam riscos}


de responsabilização subsidiária da Administração por obrigações trabalhistas sempre busquem formatos de contratações que evitem ou minimizem esses riscos. Um dos caminhos é a descrição do objeto e a estipulação de condições de pagamento com foco nos resultados a serem alcançados pelo contratado, em vez da simples intermediação de contratação de pessoal.

\section{OS PRINCÍPIOS DA EFICIÊNCIA, EFICÁCIA E EFETIVIDA- DE NO PLANEJAMENTO DA TERCEIRIZAÇÃO}

A Constituição Federal estabeleceu os princípios e as regras que regem a Administração Pública no Brasil desde a sua promulgação, em 1988, até os dias atuais. Os princípios instituídos no texto constitucional original foram os da legalidade, impessoalidade, moralidade e publicidade.

Por força do princípio da legalidade, os atos administrativos devem ser autorizados por lei, cabendo aos órgãos de controle interno, controle externo e à sociedade a fiscalização da conformidade entre a atividade estatal e a legislação vigente. Já o princípio da publicidade exige que todos os atos administrativos (exceto nos casos em que a lei autoriza o sigilo) sejam amplamente divulgados, permitindo o controle social da atividade estatal.

O princípio da impessoalidade impõe que todas as pessoas que se enquadrem em idêntica situação jurídica recebam o mesmo tratamento por parte da Administração, e o princípio da moralidade exige a conduta honesta e ética do gestor público no desempenho de suas atribuições. Esses dois princípios visam evitar que agentes públicos obtenham para si ou para outrem vantagens de qualquer natureza resultantes de atos administrativos, a exemplo dos casos de nepotismo e de corrupção.

Entre as regras estabelecidas por dispositivos constitucionais para a efetivação de tais princípios, podemos citar: a obrigatoriedade do concurso público para a admissão de servidores efetivos; as hipóteses de contratação de pessoal por tempo determinado e de provimento de cargos em comissão; a necessidade de processo licitatório para compras e contrata- 
ções públicas; a fixação de percentuais mínimos de aplicação de recursos do Tesouro na saúde e na educação; a concessão de mandado de segurança e de habeas data, respectivamente, contra ilegalidade ou abuso de poder praticado por autoridades públicas, e para garantir o acesso a informações de caráter público.

Em 1998, a Emenda Constitucional n ${ }^{0} 19$ incluiu, entre os princípios estabelecidos no art. 37 da Carta Magna, o princípio da eficiência, que, em linhas gerais, impõe a maior produtividade e economicidade possíveis na execução de ações, obras e serviços públicos. Embora a eficiência e a eficácia já estivessem previstas no inciso II do art. 74 do texto constitucional original como critérios de avaliação da gestão dos órgãos e entidades públicas federais e da aplicação de recursos públicos, a inclusão da eficiência como princípio geral impôs a obrigatoriedade de seu atendimento por todos os órgãos públicos federais, estaduais e municipais em todas as dimensões de suas atividades.

Nesse contexto, no âmbito da doutrina jurídica nacional foram formulados os princípios da eficácia e da efetividade, que mantêm com o princípio da eficiência relação de complementaridade, pois impõem, respectivamente, que ações, obras e serviços públicos sejam compatíveis com os objetivos pelos quais foram implantados e que tais resultados tragam, de fato, benefícios à população e à Administração.

Segundo Di Pietro (2006), o princípio da eficiência apresenta dois aspectos, podendo ser considerado em relação ao modo de atuação do agente público, do qual se espera o melhor desempenho possível de suas atribuições, e em relação ao modo de organizar, estruturar e disciplinar a Administração Pública; nos dois casos, com o objetivo de alcançar os melhores resultados na prestação do serviço público.

Na Proposta de Emenda $n^{\circ} 173$ de 1995, que culminou com a promulgação da Emenda Constitucional n 19 de 1998, o Poder Executivo Federal justifica que a inclusão da dimensão da eficiência da Administração Pública impõe que o Estado seja "apto a gerar mais benefícios, na forma de 
prestação de serviços à sociedade, com os recursos disponíveis, em respeito ao cidadão contribuinte" (BRASIL, 1995, p. 18852). Assim, o núcleo do princípio da eficiência é a procura de produtividade e de economicidade (CARVALHO FILHO, 2014).

A eficácia, por sua vez, está prevista no inciso II do art. 74 da Constituição Federal como critério de avaliação, pelos sistemas de controle interno, dos resultados da gestão orçamentária, financeira e patrimonial em órgãos e entidades da Administração federal, bem como da aplicação de recursos públicos por entidades de direito privado.

O princípio da eficácia impõe que o gestor público escolha a ação certa para o atendimento de cada necessidade pública ou para a solução de cada problema enfrentado pela Administração, e escolha os melhores meios para atingir esses resultados, considerando os recursos disponíveis. A atividade estatal é eficaz; portanto, quando alcança os objetivos pretendidos, sejam eles impostos por normas ou estabelecidos na fase de planejamento governamental.

Por fim, o princípio da efetividade impõe que os resultados da atividade estatal tragam benefícios concretos à população, de modo que o gestor público deve certificar-se da real necessidade e oportunidade das ações a serem tomadas. Segundo Torres (2004, p. 175), o conceito de efetividade não se relaciona estritamente à eficiência, que tem uma conotação econômica muito forte, pois nada é mais impróprio para a Administração Pública do que "fazer com eficiência o que simplesmente não precisa ser feito".

No âmbito dos órgãos de controle externo da Administração Pública, podemos citar como exemplo as definições desses três princípios formuladas pela International Organisation of Supreme Audit Institutions ${ }^{3}$ - INTOSAI, em sua International Standard of Supreme Audit Institutions ${ }^{4}$ - ISSAI 300, e pelo Tribunal de Contas Europeu, em seu Manual da Auditoria de Resultados. 
Segundo a ISSAI $300^{5}$, traduzida para o português pelo Tribunal de Contas da União, o princípio da eficiência "significa obter o máximo dos recursos disponíveis" e "diz respeito à relação entre recursos empregados e produtos entregues em termos de quantidade, qualidade e tempestividade" (INTOSAI, 2017, p. 2).

Já o princípio da efetividade "diz respeito a atingir os objetivos estabelecidos e alcançar os resultados pretendidos" (INTOSAI, 2017, p. 2). Entretanto, a nota de tradução do Tribunal de Contas da União esclarece que o termo original em inglês, effectiveness, abrange tanto o conceito de eficácia, relacionado ao grau de alcance das metas programadas em termos de produtos, quanto o conceito de efetividade, relacionado aos impactos.

Essa dupla significação explica o fato de o Tribunal de Contas Europeu ter traduzido principle of effectiveness por princípio da efetividade e ter adotado para ele a seguinte definição: "o princípio da eficácia visa a consecução dos objetivos específicos fixados e a obtenção dos resultados esperados" (UNIÃO EUROPEIA, 2017, p. 7).

Assim, é possível considerar que a eficácia se refere ao atingimento dos objetivos estabelecidos para a ação estatal, enquanto a efetividade se refere aos resultados almejados pelo Poder Público com a implementação da ação. Por exemplo, a terceirização do serviço de atendimento ao público será eficaz se o contratado disponibilizar todo o pessoal e o material exigidos pelo contrato, mas somente alcançará efetividade se o atendimento prestado atender plenamente às necessidades dos munícipes de comunicação com a Prefeitura.

Com o intuito de atender aos três princípios aqui apresentados, o planejamento das contratações de execução de serviços públicos por particulares deve contemplar, pelo menos, as seguintes etapas, previstas no Quadro 2: \begin{tabular}{l}
\hline 5 Sigla para International Standard of Supreme Audit Institutions, em português Norma Internacional das \\
Entidades Fiscalizadoras Superiores (tradução livre).
\end{tabular} 
Quadro 2 - Etapas de planejamento das contratações visando à sua eficiência, eficácia e efetividade

\begin{tabular}{|c|c|c|}
\hline Princípio & Etapas de planejamento & Procedimentos correlatos \\
\hline EFICIÊNCIA & $\begin{array}{l}\text { a) Análise do custo da execução } \\
\text { direta e comparação com os custos } \\
\text { estimados da execução por entidades } \\
\text { do Segundo Setor (por meio de } \\
\text { licitação) e da execução por entidade } \\
\text { do Terceiro Setor. }\end{array}$ & $\begin{array}{l}\text { a.1) Levantamento de custos da execu- } \\
\text { ção direta. } \\
\text { a.2) Pesquisa de mercado com empre- } \\
\text { sas do ramo. } \\
\text { a.3) Estudo da capacidade operacional } \\
\text { e custos das entidades sem fins lucrati- } \\
\text { vos do ramo. } \\
\text { a.4) Levantamento de custos de } \\
\text { realização de processo licitatório e/ou } \\
\text { chamamento público. } \\
\text { a.5) Levantamento de custos da gestão/ } \\
\text { fiscalização de contrato ou parceria } \\
\text { com entidade do Terceiro Setor. }\end{array}$ \\
\hline EFICIÊNCIA & $\begin{array}{l}\text { b) Estudos preliminares para apurar a } \\
\text { forma de execução dos serviços com } \\
\text { os menores custos diretos e indiretos. }\end{array}$ & $\begin{array}{l}\text { b.1) Execução com mão de obra } \\
\text { residente: estipulação dos resultados } \\
\text { a serem alcançados pelo contratado, } \\
\text { levantamento dos custos com a fisca- } \\
\text { lização técnica e do cumprimento de } \\
\text { obrigações acessórias (especialmente } \\
\text { previdenciárias e trabalhistas), dos } \\
\text { riscos para o contratante e das medidas } \\
\text { de redução e de contingência de riscos. } \\
\text { b.2) Execução sem mão de obra } \\
\text { residente: estipulação dos resultados } \\
\text { a serem alcançados pelo contratado, } \\
\text { levantamento dos custos de fiscaliza- } \\
\text { ção (predominantemente técnica), dos } \\
\text { riscos para o contratante e das medidas } \\
\text { de redução e de contingência de riscos. }\end{array}$ \\
\hline
\end{tabular}


Quadro 2 - Etapas de planejamento das contratações visando à sua eficiência, eficácia e efetividade (continuação)

\begin{tabular}{|c|c|c|}
\hline EFICÁCIA & $\begin{array}{c}\text { c) Elaboração do projeto básico ou } \\
\text { termo de referência (ou plano de tra- } \\
\text { balho, nas parcerias com o Terceiro } \\
\text { Setor) de modo que o detalhamento } \\
\text { do objeto e exigências garantam os } \\
\text { resultados pretendidos. }\end{array}$ & $\begin{array}{l}\text { c.1) Fixação de resultados quantitativos } \\
\text { a serem atingidos pelo contratado, tais } \\
\text { como parâmetros mínimos e máximos } \\
\text { de prazos; número de atendimentos; } \\
\text { metragem; quilometragem; volume; } \\
\text { peso; frequência etc. } \\
\text { c.2) Fixação de resultados qualitativos } \\
\text { a serem atingidos pelo contratado, tais } \\
\text { como metas ou parâmetros previstos } \\
\text { em legislação específica; pontuação } \\
\text { dos serviços pelo fiscal do contrato } \\
\text { e/ou público usuário (bom, ruim, } \\
\text { satisfatório, insatisfatório); economia } \\
\text { de insumos, tais como energia elétrica, } \\
\text { água etc. } \\
\text { c.3) Fixação de critérios objetivos de } \\
\text { mensuração dos resultados pelo fiscal } \\
\text { do contrato. }\end{array}$ \\
\hline EFETIVIDADE & $\begin{array}{c}\text { d) Verificação da conformidade } \\
\text { entre os resultados quantitativos e } \\
\text { qualitativos fixados e a demanda da } \\
\text { população ou do setor solicitante dos } \\
\text { serviços. }\end{array}$ & $\begin{array}{l}\text { d.1) Comparação entre as demandas } \\
\text { reprimida e estimada de serviços e os } \\
\text { quantitativos previstos no contrato. } \\
\text { d.2) Confirmação pelo setor solicitante } \\
\text { de que os serviços estão corretamente } \\
\text { definidos e dimensionados nas cláusu- } \\
\text { las e projetos. } \\
\text { d.3) Verificação da correção de } \\
\text { cláusulas ou partes de projetos que } \\
\text { prejudicaram a qualidade dos serviços } \\
\text { em contratos anteriores. }\end{array}$ \\
\hline
\end{tabular}

Fonte: Elaborado pela autora (2021).

A sequência de realização dessas etapas e procedimentos será diferente para cada tipo de serviço a ser contratado e de acordo com os dados e a forma de organização interna de cada município, sendo essencial que delas participem servidores e/ou empregados públicos que solicitaram a contratação, cujas atividades estejam diretamente relacionadas ao respectivo objeto e responsáveis pela gestão e fiscalização da execução do futuro contrato. 


\section{CONTRATAÇÕES COM FOCO EM RESULTADOS E NA REDUÇÃO DE RISCOS}

Esta seção é dedicada à apresentação de exemplos de formatos de contratações alternativos aos modelos que envolvem a cessão de mão de obra, não somente com o intuito de evitar a caracterização de substituição de servidores e empregados públicos, mas principalmente para implementar mecanismos de obtenção de melhores resultados quantitativos e qualitativos para o município contratante.

Em licitações de prestação de serviços de limpeza predial, por exemplo, é comum o objeto ser descrito da seguinte forma: contratação de serviço de limpeza predial, sendo sete postos de trabalho preenchidos conforme as necessidades da Administração, com jornada de trabalho de quarenta e quatro horas semanais a serem cumpridas em dias úteis das oito às dezessete horas, considerando uma hora de almoço, e aos sábados das oito às doze horas, com fornecimento de material em quantidade suficiente para a manutenção do prédio e o número de funcionários.

Em geral, o valor total da prestação de serviços nesse caso corresponde à soma dos preços unitários dos postos de trabalho, que, por sua vez, correspondem ao total dos custos trabalhistas, previdenciários, fiscais, de equipamentos de proteção individual, uniformes, seguros, custos administrativos e lucro do contratado, entre outros, rateado pelo número de postos de trabalho contratados.

O principal risco desse tipo de contrato é que o núcleo da descrição do objeto é a cessão de mão de obra, ou seja, a caracterização como despesa com pessoal, seguido do risco de caracterização da habitualidade típica das relações empregatícias nos casos em que as empresas contratadas alocam os mesmos funcionários para cada local de prestação de serviços. Soma-se a esses o risco de baixa qualidade dos serviços prestados, pois o preço é calculado e pago pelo preenchimento de cada posto de trabalho nos horários estipulados, sem considerar o desempenho de cada funcionário. 
Uma alternativa a esse formato é a estipulação de resultados a serem atingidos pelo contratado e de preços unitários por cada item atendido de forma satisfatória, independentemente do número de funcionários envolvidos na prestação dos serviços, por exemplo, conforme o Quadro 3:

Quadro 3 - Planilha de custos unitários de serviços de limpeza predial

\begin{tabular}{|l|c|}
\hline SERVIÇOS & $\mathrm{R} \$ / \mathrm{m}^{2} / \mathrm{mês}$ \\
\hline Áreas Internas - Pisos Acarpetados & 5,12 \\
\hline Áreas Internas - Pisos Frios & 5,12 \\
\hline Áreas Internas - Laboratórios & 9,3 \\
\hline Áreas Internas - Almoxarifados / Galpões & 2,27 \\
\hline Áreas Internas - Oficinas & 2,56 \\
\hline Áreas Internas Com Espaços Livres - Saguão, Hall e Salão & 3,84 \\
\hline $\begin{array}{l}\text { Áreas Internas - Sanitários de Uso Público ou Coletivo de Grande Circula- } \\
\text { ção (*) }\end{array}$ & 6,24 \\
\hline $\begin{array}{l}\text { Áreas Externas - Pisos Pavimentados Adjacentes / Contíguos às Edifica- } \\
\text { ços }\end{array}$ & 2,56 \\
\hline Áreas Externas - Varrição de Passeios e Arruamentos & 0,54 \\
\hline Áreas Externas - Pátios e Áreas Verdes - Alta Frequência & 0,49 \\
\hline Áreas Externas - Pátios e Áreas Verdes - Média Frequência & 0,24 \\
\hline Áreas Externas - Pátios e Áreas Verdes - Baixa Frequência & 0,12 \\
\hline Áreas Externas - Coleta de Detritos em Pátios e Áreas Verdes - Diária (**) & 322 \\
\hline Vidros Externos - Frequência Trimestral (Sem Exposição a Risco) & 1,6 \\
\hline Vidros Externos - Frequência Semestral (Sem Exposição a Risco) & 1,48 \\
\hline Vidros Externos - Frequência Trimestral (Com Exposição a Risco) & 2,03 \\
\hline Vidros Externos - Frequência Semestral (Com Exposição a Risco) & 1,71 \\
\hline $\begin{array}{l}* \text { (*) Cláusula do Adicional de Insalubridade do Acordo Coletivo da Categoria SIEMACO/SEAC- } \\
\text {-SP 2018 } \\
\text { (**) R\$/ha/mês (1 hectare (ha) equivale a 10.000 m²) }\end{array}$ & \\
\hline
\end{tabular}

Fonte: Extraído de CADTERC. Estudos Técnicos de Serviços Terceirizados. Volume 3 - Limpeza Predial. Disponível em: http://www.cadterc.sp.gov.br/. Acesso em: 29 abr. 2019.

Esses preços unitários devem ser multiplicados pelas quantidades de metros quadrados de cada item, pela frequência com a qual devem ser limpos e pelo período de execução dos serviços para se chegar ao valor total do contrato. 
Além de impor que o contratado seja remunerado pelos serviços efetivamente executados, contratações desse tipo oferecem critérios objetivos para a verificação da execução do objeto pelo fiscal do contrato, facilitam o cálculo do valor de itens que precisem ser acrescidos ou suprimidos (nos moldes do art. 65 da Lei $\mathrm{n}^{\mathrm{o}} 8.666 / 93$ e ar. 124 da Lei $\mathrm{n}^{\mathrm{o}}$ 14.133/2021), dificultam o enquadramento da prestação de serviços como a substituição de servidores e empregados públicos, e reduzem o risco de responsabilização da Administração por encargos trabalhistas não adimplidos pelo contratado.

Outra situação comum é a contratação de serviços de Tecnologia da Informação, especialmente o desenvolvimento e a manutenção de softwares ou sistemas informatizados para os diversos setores das Prefeituras, com o valor calculado com base na quantidade de homens-hora necessários à execução dos serviços. A fixação de preço a ser pago exclusivamente pelo critério de transcurso de período de tempo (hora, dia, mês etc.) pode se revelar antieconômica, quando pouco volume de serviços é prestado no período predeterminado.

Esse foi o entendimento expresso no voto do ministro relator do processo TC-019.998/2007-7, do Tribunal de Contas da União (Acórdão $n^{\circ}$ 2024/2007 - Plenário), pelos fundamentos de que é necessário prever metodologias de medição de serviços prestados que privilegiem a remuneração do contratado mediante a mensuração de resultados, por exemplo, na área de Tecnologia da Informação, por pontos de função.

Trata-se de método padronizado largamente utilizado no mercado para a mensuração de serviços de desenvolvimento e de manutenção de sistemas, que considera as funcionalidades efetivamente implementadas, sob o ponto de vista do usuário, buscando eliminar a possibilidade de remunerar o contratado com base na quantidade de horas trabalhadas ou nos postos de trabalho disponibilizados (Acórdão n 2024/2007 - TCU - Plenário). 
Esse mesmo critério pode ser aplicado a diversos tipos de serviços. Por exemplo, em contratações de assessoria e de consultoria, em vez de licitar os serviços por preço fixo global mensal, é possível anexar ao edital da licitação modelo de proposta que discrimine preços unitários por cada serviço a ser prestado (atendimento presencial, atendimento remoto, elaboração de parecer, revisão de documento, elaboração de laudo, auditoria de demonstrativos etc.), estabelecendo-se no contrato que os pagamentos corresponderão aos serviços efetivamente prestados pelo contratado em cada período de apuração.

Caso a medição por funções ou por produtos não seja comprovadamente viável, restando como única opção a remuneração de serviços por horas trabalhadas, é importante adotar providências no sentido de que sejam previamente definidos e especificados os serviços a serem executados e estabelecidos os valores máximos de horas aceitáveis para cada um desses serviços, assim como explicitada a metodologia a ser utilizada para a fixação desse quantitativo de horas (Acórdão nº 2024/2007 - TCU - Plenário).

Por fim, quando as etapas de planejamento apontarem como melhor solução para a demanda da Administração, do ponto de vista técnico e de economicidade, contrato que envolva a disponibilização de postos de trabalho, é prudente que se adotem medidas no sentido de exigir, no processo licitatório, planilha de custos unitários que diferencie as despesas com mão de obra dos demais custos da execução do objeto, como o fornecimento de material e equipamentos, de modo a evitar que estes últimos sejam computados nas despesas com pessoal de que trata a Lei de Responsabilidade Fiscal (BRUNO, 2011).

\section{TERCEIRIZAÇÃO DE SERVIÇOS DE SAÚDE}

O $\S 1^{\circ}$ do art. 199 da Constituição Federal autoriza que as instituições privadas participem de forma complementar do Sistema Único de Saúde (SUS), segundo diretrizes deste, mediante contrato de direito público ou con- 
vênio, tendo preferência as entidades filantrópicas e as sem fins lucrativos.

O art. 130 da Portaria de Consolidação $n^{\circ}$ 1/2017 do Ministério da Saúde estabelece que o gestor competente do SUS poderá recorrer aos serviços de saúde ofertados pela iniciativa privada quando a oferta de ações e serviços de saúde públicos próprios forem insuficientes e comprovada a impossibilidade de ampliação para garantir a cobertura assistencial à população de um determinado território.

Desse modo, a primeira fase do processo administrativo referente tanto à celebração de parceria com entidade do Terceiro Setor quanto à realização de processo licitatório deve ser dedicada ao levantamento dos dados relativos à estrutura física e aos recursos humanos e materiais próprios disponíveis e da respectiva capacidade operacional, para a devida comprovação de que são insuficientes para o atendimento da demanda reprimida de serviços, que também deve ser criteriosamente levantada. Em seguida, devem ser realizados os levantamentos de custos da ampliação de estrutura física, recursos humanos e/ou materiais necessários à satisfação dessa demanda, para que constem, também, no processo.

Presentes os requisitos exigidos pelo citado art. 130, deve ser estudada a possibilidade de atendimento da demanda por entidades filantrópicas e/ ou sem fins lucrativos, cuja participação não é formalizada apenas mediante convênios, pois a legislação nacional prevê outras modalidades, apresentadas na seção seguinte deste artigo, que tratam das parcerias com o Terceiro Setor.

Restando apenas a possibilidade de buscar os serviços no mercado, é necessária sua precisa caracterização, com estipulação dos resultados a serem exigidos e dos respectivos custos unitários, que, por força do $\S 6^{\circ}$ do citado art. 130, devem ter como referência a Tabela de Procedimentos do SUS. As definições de serviços e preços da Tabela são disponibilizados pelo Sistema de Gerenciamento da Tabela de Procedimentos, Medicamentos e OPM do SUS - SIGTAP, na internet, no endereço http://sigtap.datasus.gov.br/tabela-unificada/app/sec/inicio.jsp (Acesso em: 29 abr. 2019). 
Além da possibilidade de contratação de prestadores de serviços de saúde com fins lucrativos por meio de licitação, a Lei no 14.133/2021 traz, entre as hipóteses de inexigibilidade, os "objetos que devam ou possam ser contratados por meio de credenciamento". No âmbito do SUS, trata-se de procedimento pelo qual a Administração Pública, após chamamento público para um determinado objeto, celebra contrato de prestação de serviços com todos aqueles considerados aptos, nos moldes do art. 129, inciso II, da Portaria de Consolidação n ${ }^{\circ} 1 / 2017^{6}$.

Ressalte-se que o credenciamento formal das entidades privadas somente será admitido se devidamente justificado pelo gestor competente e nas hipóteses em que houver necessidade de um maior número de prestadores para o mesmo objeto e a competição entre eles for inviável (art. 132, $\S 1^{\circ}$, da Portaria de Consolidação $\left.n^{\circ} 1 / 2017\right)$. O respectivo processo administrativo de inexigibilidade deve ser instruído com a razão da escolha dos executantes e a justificativa dos preços fixados (art. 26 da Lei no 8.666/93).

A partir dos arts. 128 a 138 da citada Portaria de Consolidação ${ }^{\circ}$ 1/2017 e dos art. 25 a 31, 67, 78 e 79 da Lei no 8.666/93, é possível delinear as seguintes etapas do processo de credenciamento:

Quadro 4 - Processo de credenciamento de prestadores de serviços de saúde

\begin{tabular}{|l|l|}
\hline ETAPAS & PROCEDIMENTOS \\
\hline & $\begin{array}{l}\text { O edital e o respectivo regulamento do chama- } \\
\text { mento público deverão ser disponibilizados no } \\
\text { Diário Oficial correspondente, em jornais de } \\
\text { grande circulação e por meios eletrônicos, con- }\end{array}$ \\
$\begin{array}{l}\text { 1) Chamamento público: ato de chamar, publi- } \\
\text { camente, prestadores de serviços assistenciais } \\
\text { credenciá-los. }\end{array}$ & $\begin{array}{l}\text { tendo o prazo de inscrição. Os requisitos para } \\
\text { o credenciamento devem estar previstos no res- } \\
\text { pectivo regulamento, garantindo-se isonomia } \\
\text { entre os interessados dispostos a contratar pelos } \\
\text { valores definidos pelo SUS, constantes, obriga- } \\
\text { toriamente, no edital. }\end{array}$ \\
\hline
\end{tabular}

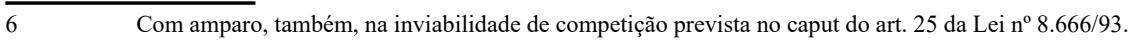


Quadro 4 - Processo de credenciamento de prestadores de serviços de saúde (continuação)

2) Inscrição: preenchimento, pelas entidades interessadas, de formulário próprio disponibilizado pelo ente federado contratante, acompanhado dos documentos previstos no respectivo regulamento, que serão encaminhados à comissão responsável.

3) Cadastro: registro, pelo ente federado contratante, das informações apresentadas junto com o formulário de inscrição, como o nome da entidade, endereço, descrição da atividade econômica, natureza jurídica, entre outros dados que são de interesse da Administração.

4) Visita técnica para qualificação: inspeção realizada pelo ente federado contratante à entidade cadastrada com o objetivo de identificar e avaliar a capacidade física e operacional, e a qualidade das ações e dos serviços prestados, com a emissão de parecer circunstanciado, que fundamentará a decisão acerca da habilitação da entidade.

5) Habilitação: consiste na análise dos documentos entregues no ato de inscrição e parecer emitido por ocasião da visita técnica do ente federado contratante.

A documentação deve comprovar os requisitos dos arts. 27 a 31 da Lei no 8.666/93 e o registro no Cadastro Nacional de Estabelecimentos de Saúde (CNES).

Devem ser emitidos os Certificados de Registro Cadastral - CRC das entidades interessadas. O registro de dados cadastrais para credenciamento estará permanentemente aberto a futuros interessados, estabelecidos os limites temporais para as contratações.

(não há previsão de procedimentos específicos relativos à visita técnica)

Devem ser inabilitados os licitantes que não preencham qualquer dos requisitos dos arts. 27 a 31 da Lei $\mathrm{n}^{\circ} 8.666 / 93$ ou que não possuam registro no CNES.

O termo deve exigir que o contratado: submeta-se a avaliações sistemáticas pela gestão do SUS, à regulação instituída pelo gestor e ao Sistema Nacional de Auditoria do SUS (SNA) e seus componentes (apresentando toda documentação necessária, quando solicitado); apresente, sempre que solicitado, relatórios de atividade que demonstrem, quantitativa e qualitativamente, $o$ atendimento do objeto pactuado; assegure a veracidade das informações prestadas ao SUS; cumpra todas as normas relativas à preservação do meio ambiente; e preencha os campos referentes ao contrato no Sistema de Cadastro Nacional de Estabelecimentos de Saúde (SCNES).

7) Publicação: como condição de eficácia dos atos, o gestor do SUS deverá publicar extrato da contratação na imprensa oficial, no prazo de cinco dias, por força do que dispõe o art. $26 \mathrm{da}$ Lei ${ }^{\circ} 8.666 / 93$.

Deve haver, também, divulgação do extrato da contratação em meio eletrônico. 
Quadro 4 - Processo de credenciamento de prestadores de serviços de saúde (continuação)

8) Fiscalização: verificação do cumprimento das condições descritas no instrumento contratual, nos termos do art. 67 da Lei $n^{\circ} 8.666 / 93$.

9) Descredenciamento: rescisão contratual entre a entidade credenciada e o ente contratante, após regular processo administrativo, com observância aos princípios do contraditório e da ampla defesa.

Fonte: Elaborado pela autora (2021).

Embora do credenciamento se originem vários contratos para a execução do mesmo objeto, a Portaria de Consolidação $n^{\circ}$ 1/2017 não estabelece regras explícitas quanto à forma de distribuição da demanda de serviços entre os prestadores contratados. Sobre essa questão, no Acórdão no 352/2016, o Tribunal de Contas da União determinou ao Ministério da Saúde que oriente todos os entes federativos a observar, entre outras diretrizes, a necessidade de desenvolver, nas contratações por credenciamento, metodologia para a distribuição dos serviços entre os interessados de forma objetiva e impessoal.

Quanto à forma de medição e condições de pagamento a serem pactuadas nos contratos dessa espécie, o citado Acórdão traçou as seguintes diretrizes:

9.1.3. devem ser realizados estudos que indiquem qual sistema de remuneração dos serviços prestados é mais adequado para o caso específico do objeto do ajuste a ser celebrado, levando em consideração que a escolha da forma de pagamento por tempo, por procedimentos, por caso, por captação ou a combinação de diferentes métodos de remuneração possui impacto direto no volume e na qualidade dos serviços prestados à população;

9.1.4. os processos de pagamento das entidades contratadas devem estar suportados por documentos que comprovem que os serviços foram efetivamente prestados - demonstrando o controle da frequência dos profissionais, os procedimentos realizados, os pacientes atendidos - e que garantam que os impostos, taxas e encargos trabalhistas aplicáveis ao caso foram devidamente recolhidos." (Acórdão no 352/2016 TCU - Plenário, grifos nossos) 
Dessas diretrizes, depreende-se a importância de que a execução indireta tenha como foco a eficiência, a eficácia e a efetividade dos serviços públicos de saúde prestados, além da mitigação dos riscos de prejuízos para o município contratante, decorrentes do inadimplemento de obrigações acessórias pelos contratados.

Com o advento da Lei $\mathrm{n}^{\circ} 14.133 / 2021$, há a possibilidade de que seja necessária a revisão dos arts. 128 a 138 da citada Portaria de Consolidação $\mathrm{n}^{\circ} 1 / 2017$ quanto aos procedimentos e às etapas da modalidade do credenciamento.

\section{PARCERIAS COM O TERCEIRO SETOR E A PORTARIA NO 233/19 DA SECRETARIA DO TESOURO NACIONAL}

Além da contratação de prestação de serviços por meio de processos licitatórios, o município tem também a opção de firmar parcerias com entidades do Terceiro Setor.

O movimento de redefinição das estruturas da Administração Pública ocorrido durante a década de 1990 (mesmo contexto no qual foi promulgada a Emenda Constitucional no 19/98) foi o grande ponto de inflexão para a análise acerca dos distintos institutos que conformam a realidade das instituições não governamentais voltadas ao atendimento de demandas coletivas de distintas naturezas, que compõem o chamado "Terceiro Setor" (PORTELLA, 2010).

O Direito pátrio contempla apenas cinco formas de constituição de personalidade jurídica de direito privado: a fundação, a associação, a sociedade, o partido político e a entidade religiosa, sendo que, a princípio, apenas as duas primeiras são passíveis de constituição de entidades do Terceiro Setor (PORTELLA, 2010). Podemos citar as seguintes características e diferenças entre elas: 


\begin{abstract}
As Fundações são pessoas jurídicas constituídas a partir de um acervo patrimonial a ser administrado pela instituição, podendo possuir distintos objetos, dentre os quais aqueles voltados à assistência social. Uma certa resistência à constituição de entidades do terceiro setor com natureza jurídica fundacional é explicada pela existência de entraves jurídicos relativos sobretudo à rigidez da sua fiscalização por parte do Ministério Público, além do controle a cargo dos Tribunais de Contas, em função dos recursos públicos eventualmente recebidos. As associações, por outro lado, são pessoas jurídicas de direito privado constituídas a partir da reunião de um conjunto de indivíduos, com objetivo comum, incluído o objetivo filantrópico. São certamente as figuras jurídicas mais comumente utilizadas para fins de instituição de entidades do terceiro setor. (PORTELLA, 2010, p. 273)
\end{abstract}

A Lei Federal no 13.019/14, conhecida como "Marco Regulatório do Terceiro Setor", estabelece o regime jurídico das parcerias entre a Administração Pública e as organizações da sociedade civil, em regime de mútua cooperação, para a consecução de finalidades de interesse público e recíproco, mediante a execução de atividades ou de projetos previamente estabelecidos em planos de trabalho inseridos em termos de colaboração, em termos de fomento ou em acordos de cooperação.

São consideradas, pela citada lei, organizações da sociedade civil as entidades privadas sem fins lucrativos; as sociedades cooperativas previstas na Lei no 9.867/99; as integradas por pessoas em situação de risco ou de vulnerabilidade pessoal ou social; as alcançadas por programas e ações de combate à pobreza e de geração de trabalho e renda; as voltadas para fomento, educação e capacitação de trabalhadores rurais ou capacitação de agentes de assistência técnica e extensão rural; e as capacitadas para execução de atividades ou de projetos de interesse público e de cunho social, bem como as organizações religiosas que se dediquem a atividades ou a projetos de interesse público e de cunho social distintas das destinadas a fins exclusivamente religiosos. Ou seja, o Marco Regulatório trouxe a possibilidade de parcerias também com entidades não constituídas como 
fundação ou associação, desde que se enquadrem nas hipóteses de seu art. $2^{\circ}$, inciso I.

O termo de colaboração é o instrumento por meio do qual são formalizadas as parcerias estabelecidas pela Administração Pública com organizações da sociedade civil para a consecução de finalidades de interesse público e recíproco propostas por órgão ou entidade pública que envolvam a transferência de recursos financeiros, enquanto no termo de fomento os planos de trabalho são propostos pelas organizações da sociedade civil (art. $2^{\circ}$, incisos VII e VIII, da Lei Federal no 13.019/14).

Já o acordo de cooperação é o instrumento por meio do qual são formalizadas as parcerias estabelecidas pela Administração Pública com organizações da sociedade civil para a consecução de finalidades de interesse público e recíproco que não envolvam a transferência de recursos financeiros (art. $2^{\circ}$, inciso VIII-A, da Lei Federal no 13.019/14).

Em regra, a celebração de termo de colaboração ou de fomento e o acordo de cooperação cujo objeto envolva a celebração de comodato, doação de bens ou outra forma de compartilhamento de recurso patrimonial deve ser precedida de chamamento público voltado a selecionar organizações da sociedade civil que tornem mais eficaz a execução do objeto pretendido pela Administração, e a prestação de contas é obrigatória em todos os casos (art. 42, inciso VII, da Lei Federal no 13.019/14).

Além das três modalidades de parcerias com o Terceiro Setor instituídas pela Lei Federal no 13.019/14, outros instrumentos regulamentados por leis anteriores ao Marco Regulatório continuam vigentes e podem ser adotados pelos municípios conforme as necessidades e as peculiaridades de cada caso, sendo os mais comuns o convênio, o contrato de gestão, o termo de parceria e a parceria público-privada.

Tais instrumentos têm em comum a possibilidade de execução, pelo parceiro privado (sem fins lucrativos), de atividades finalísticas da Administração. Não por outra razão, o Manual de Demonstrativos Fiscais da Secretaria do Tesouro Nacional ( $9^{\mathrm{a}}$ edição) determina a inclusão na 
despesa de pessoal dos valores de contratações indiretas de "serviços públicos relacionados à atividade fim do ente público, ou seja, por meio da contratação de cooperativas, de consórcios públicos, de organizações da sociedade civil, do serviço de empresas individuais ou de outras formas assemelhadas" (BRASIL, 2018, p. 495).

De acordo com a Portaria da Secretaria do Tesouro Nacional $\mathrm{n}^{\circ}$ 377/2020, os prazos de definição das rotinas e das contas contábeis, de adequação dos dispositivos contratuais e dos procedimentos de prestação de contas e de cômputo das despesas com pessoal das organizações da sociedade civil nos limites previstos no art. 19 da Lei Complementar $\mathrm{n}^{\circ}$ 101/2000 se encerram, respectivamente, no final do exercício de 2020, no final do exercício de 2021 e no exercício de 2022 (BRASIL, 2020). Isto é, a citada inclusão das despesas de pessoal das entidades do Terceiro Setor de que trata o Manual de Demonstrativos Fiscais da Secretaria do Tesouro Nacional ( $9^{a}$ edição) deverá ocorrer a partir do exercício de 2022, impactando os resultados fiscais de todos os entes da federação.

O desafio para os municípios, nesse contexto, é o de conciliar a importância da gestão responsável em épocas de crise econômica com a necessidade de atendimento à população, principalmente a população mais carente, que é a mais afetada por essa mesma crise. Ou seja, buscar mecanismos de otimização e de racionalização dos recursos destinados à remuneração de pessoal das entidades do Terceiro Setor, de modo que sua adequação aos limites da Lei Fiscal não comprometa o atingimento das finalidades das parcerias firmadas com tais entidades.

\section{CONCLUSÃO}

Momentos de crises exigem reflexões sobre o sentido das leis e as funções primordiais do Estado que levem a reformulações das práticas adotadas pela Administração Pública na busca pelo atendimento às demandas da população. 
A alternativa de se substituir os contratos que envolvem a simples troca de servidores e empregados públicos por contratos cujo objeto é o resultado alcançado pelo contratado na execução quantitativa e qualitativa de serviços representa não apenas um caminho viável para a redução de despesas com pessoal, do ponto de vista da Lei de Responsabilidade Fiscal, mas também a busca pelo atendimento aos princípios da eficiência, eficácia e efetividade consagrados no contexto da aprovação da Emenda Constitucional no 19/98. De igual modo, a legislação que rege os serviços do Sistema Único de Saúde e as parcerias com o Terceiro Setor oferece mecanismos de busca por resultados que vão além da simples disponibilização de pessoal para o atendimento à população.

A legislação e os entendimentos doutrinários e de órgãos de controle externo apresentados neste artigo evidenciam que essa alternativa envolve, principalmente, o planejamento criterioso e detalhado das diferentes formas de execução indireta de serviços públicos, buscando-se a melhor alternativa em termos de redução de custos e de riscos, e em termos de atendimento real das necessidades da Administração, além dos procedimentos de fiscalização e de acompanhamento do cumprimento das obrigações principais e acessórias estipuladas em todos os ajustes firmados com a iniciativa privada.

Isto é, o Direito pátrio, há muito tempo, vem criando mecanismos de solução de problemas de gestão fiscal e de garantia da prestação dos serviços públicos; mecanismos cuja relevância se acentua à medida que se agravam as crises políticas e econômicas no país.

\section{REFERÊNCIAS}

BRASIL. [Constituição (1988)]. Constituição da República Federativa do Brasil. Proposta de Emenda Constitucional no 173, de 1995. Diário Oficial [da] República Federativa do Brasil: seção 1, Brasília, DF, 18 ago. 1995. p. 18849-18854. 
BRASIL. Conselho Nacional de Justiça. Manual de gestão de contratos. Brasília: Conselho Nacional de Justiça, 2013. 54 p.

BRASIL. Secretaria do Tesouro Nacional. Manual de demonstrativos fiscais: aplicado à União e aos estados, Distrito Federal e municípios. Brasília: Secretaria do Tesouro Nacional, Subsecretaria de Contabilidade Pública, Coordenação Geral de Normas de Contabilidade Aplicadas à Federação, 2018. 654 p.

BRASIL. Ministério do Planejamento, Desenvolvimento e Gestão. Instrução Normativa $\mathbf{n}^{0}$ 5, de 26 de maio de 2017. Disponível em: https://www.in.gov.br/materia/-/asset_publisher/Kujrw0TZC2Mb/content/ id/20239255/do1-2017-05-26-instrucao-normativa-n-5-de-26-de-maio-de-2017-20237783. Acesso em: 21 abr. 2021.

BRASIL. Secretaria do Tesouro Nacional. Portaria $\mathrm{n}^{\circ} 377$, de 8 de julho de 2020. Estabelece prazos para a definição de rotinas e contas contábeis, bem como classificações orçamentárias para operacionalização do item 04.01.02.01 (3) da 10 edição do Manual de Demonstrativos Fiscais (MDF), aprovado pela Portaria STN no 286, de 7 de maio de 2019, e alterações posteriores. Diário Oficial da União, Brasília, DF, n. 130, 9 jul. 2020.

BRASIL. Tribunal de Contas da União. Licitações e contratos: orientações e jurisprudência do TCU. Brasília: TCU, Secretaria-Geral da Presidência: Senado Federal, Secretaria Especial de Editoração e Publicações, 2010. $910 \mathrm{p}$.

BRUNO, R. M. Lei de Responsabilidade Fiscal e orçamento público municipal. Curitiba: Juruá, 2011. 300 p. 
CADTERC. Estudos Técnicos de Serviços Terceirizados. Volume 3 Limpeza Predial. Disponível em: http://www.cadterc.sp.gov.br/. Acesso em: 29 abr. 2019.

CARVALHO FILHO, J. S. Manual de Direito Administrativo. São Paulo: Atlas, 2014. $1311 \mathrm{p}$.

DI PIETRO, M. S. Z. Direito Administrativo. São Paulo: Atlas, 2006. $823 \mathrm{p}$.

DI PIETRO, M. S. Z. Parcerias na Administração Pública: concessão, permissão, franquia, terceirização, parceria público-privada e outras formas. São Paulo: Atlas, 2012. 465 p.

INTOSAI. ISSAI 300: princípios fundamentais de auditoria operacional. Brasília: Tribunal de Contas da União, 2017. 16 p.

JUSTEN FILHO, M. Comentários à Lei de Licitações e Contratos Administrativos. 14. ed. São Paulo: Dialética, 2010. 991 p.

PORTELLA, A. A competência fiscalizadora dos tribunais de contas sobre as entidades do terceiro setor. Revista Jurídica da Presidência, Brasília: Presidência da República/Casa Civil/Subchefia para Assuntos Jurídicos, v. 12, n. 97, p. 258-284, jun./set. 2010.

TORRES, M. D. F. Estado, democracia e Administração Pública no Brasil. Rio de Janeiro: Editora FGV, 2004. 224 p.

UNIÃO EUROPEIA. Tribunal de Contas Europeu. Manual da auditoria de resultados. Luxemburgo: Tribunal de Contas Europeu, 2017. 97 p. 